\title{
Editorial
}

\section{A New Year Brings Change to the GLJ}

\author{
Maria Lorena Cook, Cornell University, USA \\ Madhumita Dutta, The Ohio State University, USA \\ Alexander Gallas, University of Kassel, Germany \\ Ben Scully, University of the Witwatersrand, South Africa
}

A new year often brings changes, and so it is with us. While our goal for the Journal to cover important topics relating to workers and labour activities around the globe remains the same, we face several departures from the GLJ team and will be welcoming some new faces.

This is Jörg Nowak's last issue as Reviews Editor, a position he has held for more than four years. Jörg ensured that reviews of important books on a range of topics in the labour field appeared regularly. He led our efforts to include non-English-language books among those reviews, and to publish some of the reviews in languages other than English on our website. Jörg was also an important presence on our Editorial Board; his knowledge of labour issues has a global reach from Europe to India to Latin America - which, together with his wide range of global contacts, greatly enriched our discussions and benefited the GLJ. We wish him all the best in his endeavours at the Universidade de Brasilia in Brazil, where he has recently taken up a position.

Madhumita Dutta is stepping down as a member of the Editorial Board. A geographer based at The Ohio State University, Madhu brought key perspectives on gender, inequality and the Global South to the work of the Board. We wish her all the best as she continues to pursue her important research on the everyday politics of labour, life stories of workers, and women and work.

Tasmeen Essop's role in maintaining our social media platforms has been indispensable. Tasmeen, based at the University of the Witwatersrand, has diligently posted new material to our Facebook and Twitter accounts, tracked our views, likes and retweets, and made improvements to our social media presence. We thank her and wish her well as she completes her $\mathrm{PhD}$ in Sociology at the University of the Witwatersrand.

As much as we will miss these colleagues, we are excited to be joined by new members of our team.

Omar Manky Bonilla, from the Universidad del Pacífico in Lima, Peru, will step in as Reviews Editor. Omar holds a PhD in Industrial and Labour Relations from Cornell University. His research has focused on trade union dynamics in the mining sector in Latin America and on the transformation of academic work in Peruvian universities.

Christopher Raymond will take over as GLJ's social media coordinator. He is completing his $\mathrm{PhD}$ in industrial relations at Cornell University. His research focuses on labour transnationalism in South Asian apparel supply chains.

We are currently in the process of finding a replacement for Madhumita Dutta's position on the Editorial Board and will make an announcement in due course.

We look forward to working with our new colleagues, and to another year of the GLJ. Please help us make the Journal even more productive, relevant and engaging in 2022 by submitting your articles, global issues pieces and book review suggestions to us. 